\title{
TOTAL OXYGEN CONSUMPTION AND METABOLIC RATE OF PATIENTS IN DIABETIC ACIDOSIS ${ }^{1}$
}

\author{
By PETER FISHER ${ }^{2}$ AND JEROME I. KLEINERMAN 3
}

\author{
(From the Diabetic Coma Project, Metabolic Laboratories, Philadelphia General Hospital, and \\ Department of Physiology and Pharmacology, Graduate School of Medicine, \\ University of Pennsylvania, Philadelphia, Pa.)
}

(Submitted for publication March 9, 1951; accepted October 29, 1951)

There is little information on the metabolic rate of patients in severe acidosis resulting from uncontrolled diabetes mellitus, and among the few studies which have been reported, there is no general uniformity of results. It has usually been concluded that there is no striking change in metabolic rate of patients in diabetic acidosis. Recent studies in this laboratory do not confirm these reports, and the changes found have been consistent and definite.

Many of the early studies included patients who were in mild or questionable acidosis, and comparison of their metabolic rates to normal were made on a simple height : weight relationship rather than on the more valid DuBois standards (1) which comprehend body surface area. Allen and DuBois (2) in 1916, Wilder and associates (3) in 1922, and Holton (4) in 1924, all presented complete reviews, including the studies of Hédon (5), Joslin and Bennedict (cited in [2]) and Bernstein and Falta (6). These reviewers agreed that the previous investigators obtained variable results and that the most reasonable conclusion was that there is no significant or striking change of the metabolic rate of patients in diabetic acidosis as compared to normal. Richardson and Mason (7) studied a case of diabetic coma in a "respiration calorimeter" and found an increase in the basal metabolic rate of 11 per cent. Duncan (8) as late as 1947 listed diabetic acidosis under the category of miscellaneous disorders which caused clinically unimportant changes in the basal metabolic rate. Joslin and associates (9) agreed with all previous reviewers and quoted the statement of DuBois (10): "The role of acidosis in the metabolism of a diabetic is ex-

1 This investigation was supported by a research grant from the National Heart Institute, U. S. Public Health Service.

2 Present address: Guthrie Clinic, Sayre, Pennsylvania.

8 Present adress : Department of Pathology, Cleveland City Hospital, Cleveland, Ohio. tremely complicated, and I doubt if it will ever be definitely settled. At the present time it seems as if a severe acidosis might cause a moderate increase in metabolism in some cases of diabetes."

\section{METHOD}

Each patient was studied immediately upon admission to the ward and before any treatment was given. A general statement regarding the procedure was given to the patients so as to prevent undue anxiety associated with holding a mask over the face. The method of indirect calorimetry with an open circuit was used. By means of a well fitting face mask, the patient breathed room air. His total expired air was collected in a calibrated Tissot spirometer. All patients were hyperventilating so that it required a collection of but two to four minutes to fill the spirometer completely. A preliminary collection was first made to wash out the spirometer and to accustom the patient to the procedure. The total gas expired per unit of time was calculated. Corrections were made for barometric and vapor pressure and temperature to reduce all figures to standard conditions. Samples of the gas in the spirometer were transferred immediately to Bailey bottles and analysed in a Haldane apparatus for oxygen and carbon dioxide content. Oxygen consumption per minute and basal metabolic rate were calculated from these data by standard formulae (11).

\section{RESULTS}

Table I summarizes the results obtained on patients in diabetic acidosis, two of whom were also studied after therapy when they were no longer in acidosis. The data presented include all patients upon whom respiratory studies were performed. Every patient proved to have a significant hyperglycemia and hyperketonemia diagnostic of uncontrolled diabetes mellitus. It can be seen that in every case but one, the basal metabolic rate was significantly greater than normal, the highest being +77 and the average being +41.4 . Patient F. P., having a basal metabolic rate of +19 before therapy, returned to +7 when her diabetes was 
controlled and patient J. M. decreased from +25 to +3 .

Seven non-diabetic patients studied in the same way were used as controls to rule out any systematic errors in the methods employed or in the effect of the procedure itself on the metabolic rate. The results vary greatly since these patients were not true normals, all being hospitalized for various disorders; they were selected on the basis of near normality, being afebrile and without known acute disease and were ready for discharge from the hospital for their particular illnesses. They were studied under standard basal conditions. Four patients had positive values and three negative, the average being -2.7 . No systematic deviation was found in the control group, and there was a highly significant difference in the basal metabolic rate between the control group and the patients in diabetic acidosis $(\mathrm{P}<0.01)$.

Since all of the patients in acidosis were hyperventilating, a control experiment was performed to determine the effect of moderate hyperventilation on oxygen consumption and metabolic rate. Subjects were healthy young physicians or medical students, not necessarily fasting. Subjects rested from 30 to 45 minutes prior to collection of expired gas. A resting volume was then collected for periods of two to four minutes. Oxygen concentration in the expired air was calculated from the oxygen tension measured by a Pauling oxygen meter which had been previously calibrated against gas mixtures of known concentration-these gas mixtures having been analyzed by a Scholander micro-gas analysis apparatus. Oxygen consump-

TABLE I

Basal metabolic rate in diabetic acidosis compared to non-diabetic controls

\begin{tabular}{|c|c|c|c|c|c|c|c|c|c|c|c|}
\hline Patient & $\begin{array}{c}\text { Age } \\
(y r s .)\end{array}$ & Sex & $\underset{(\mathrm{cm} .)}{\text { Height }}$ & $\underset{(\text { kg.) }}{\text { Weight }}$ & $\begin{array}{c}\text { Arterial } \\
\text { blood } \\
\mathrm{CO}_{2} \\
\text { content } \\
\text { (vol. \%) }\end{array}$ & $\begin{array}{c}\text { Arterial } \\
\text { blood } \\
\text { pH }\end{array}$ & $\begin{array}{c}\text { Mental } \\
\text { state* }\end{array}$ & $\begin{array}{l}\text { Respiratory } \\
\text { volume } \\
\text { (liters/min.) }\end{array}$ & R.Q. & $\begin{array}{c}\text { Oxygen } \\
\text { consumption } \\
(c c . / m i n .)\end{array}$ & B.M.R. \\
\hline
\end{tabular}

Patients in diabetic acidosis-before therapy

\begin{tabular}{l|l|l|l|l|l|l|l|l|l|l|l|l}
\hline F. P. & 60 & F & 173 & 110 & 25.0 & 7.39 & 1 & 10.1 & 0.63 & 313 & +19 \\
C. C. & 50 & M & 185 & 96 & 8.3 & 6.94 & 2 & 22.6 & 0.56 & 386 & +31 \\
J. S. & 36 & M & 170 & 73 & 20.4 & 7.27 & 1 & 15.1 & 0.62 & 434 & +62 \\
N. D. & 53 & F & 155 & 61 & $14.2 \dagger$ & $7.28 \dagger$ & 2 & 13.4 & 0.56 & 280 & +57 \\
J. M. & 18 & M & 170 & 50 & 10.4 & 7.12 & 2 & 15.3 & 0.63 & 289 & +25 \\
S. B. & 49 & M & 168 & 52 & 7.8 & 7.14 & 1 & 20.8 & 0.72 & 283 & +35 \\
G. F. & 19 & M & 173 & 47 & 14.6 & 7.18 & 1 & 13.9 & 0.76 & 303 & +27 \\
N. C. & 43 & M & 170 & 50 & 29.6 & 7.21 & 1 & 8.9 & 0.63 & 225 & +3 \\
A. O. & 38 & F & 165 & 67 & 8.6 & 7.19 & 2 & 21.1 & 0.61 & 351 & +54 \\
H. J. & 50 & M & 163 & 56 & $13.0 \dagger$ & $7.13 \dagger$ & 1 & 19.2 & 0.64 & 352 & +65 \\
H. R. & 35 & M & 180 & 60 & 11.1 & 7.14 & 2 & 18.1 & 0.49 & 484 & +77 \\
Mean & 44 & & 170 & 66 & 14.8 & 7.18 & & 16.2 & 0.62 & 336 & $+41.4 \pm$ s.e. 6.9 \\
\hline
\end{tabular}

Patients in diabetic acidosis-after therapy

\begin{tabular}{l|l|l|l|l|l|l|l|l|l|l|l}
\hline F. P. & 60 & $\mathrm{~F}$ & 173 & 110 & 66.2 & 7.43 & 1 & 7.7 & 0.80 & 270 & +7 \\
J. M. & 18 & $\mathrm{M}$ & 170 & 50 & 47.5 & 7.41 & 1 & 7.6 & 0.81 & 228 & +3 \\
\hline
\end{tabular}

Hospital patients without diabetes

\begin{tabular}{|c|c|c|c|c|c|c|c|c|c|c|c|}
\hline $\begin{array}{l}\text { R. S. } \\
\text { L. S. } \\
\text { T. C. } \\
\text { M. J. } \\
\text { B. F. } \\
\text { E. L. } \\
\text { A. D. }\end{array}$ & $\begin{array}{l}19 \\
31 \\
34 \\
38 \\
58 \\
47 \\
38\end{array}$ & $\begin{array}{l}\mathbf{M} \\
\mathbf{M} \\
\mathbf{M} \\
\mathbf{F} \\
\mathbf{M} \\
\mathbf{F} \\
\mathbf{M}\end{array}$ & $\begin{array}{l}168 \\
180 \\
170 \\
155 \\
170 \\
157 \\
168\end{array}$ & $\begin{array}{r}77 \\
67 \\
61 \\
43 \\
117 \\
73 \\
50\end{array}$ & $\begin{array}{l}53.2 \\
50.6 \\
48.6 \\
49.8 \\
52.0 \\
52.3 \\
53.8\end{array}$ & $\begin{array}{l}7.49 \\
7.47 \\
7.22 \\
7.46 \\
7.42 \\
7.39 \\
7.49\end{array}$ & $\begin{array}{l}1 \\
1 \\
1 \\
1 \\
1 \\
1 \\
1 \\
1\end{array}$ & $\begin{array}{l}5.3 \\
5.3 \\
9.2 \\
8.1 \\
9.6 \\
4.0 \\
5.9\end{array}$ & $\begin{array}{l}0.65 \\
0.72 \\
0.88 \\
1.08 \\
0.76 \\
0.73 \\
0.68\end{array}$ & $\begin{array}{l}308 \\
153 \\
272 \\
149 \\
410 \\
143 \\
250\end{array}$ & $\begin{array}{l}+12 \\
-41 \\
+11 \\
-12 \\
+37 \\
-36 \\
+10\end{array}$ \\
\hline Mean & 38 & & 167 & 70 & 51.5 & 7.42 & 1 & 6.8 & 0.79 & 241 & $-2.7 \pm$ s.e. 10.7 \\
\hline
\end{tabular}

* Mental state is described as: grade 1, normal; grade 2, lethargic, confused.

$\uparrow$ Venous blood. 
TABLE II

The effect of moderate hyperventilation on oxygen consumption and metabolic rate

\begin{tabular}{|c|c|c|c|c|c|c|c|c|c|}
\hline \multicolumn{2}{|c|}{ Subject } & \multirow{2}{*}{$\begin{array}{c}\text { Age } \\
y r s . \\
29\end{array}$} & \multirow{2}{*}{$\begin{array}{l}\text { Sex } \\
\\
M\end{array}$} & \multirow{2}{*}{$\begin{array}{c}\text { Height } \\
\begin{array}{c}c m . \\
171\end{array}\end{array}$} & \multirow{2}{*}{$\begin{array}{c}\text { Weight } \\
\begin{array}{c}k g . \\
77\end{array}\end{array}$} & \multirow{2}{*}{$\begin{array}{c}\begin{array}{c}\text { Respiratory } \\
\text { volume }\end{array} \\
\text { liters/min. } \\
5.8 \\
14.3\end{array}$} & \multicolumn{2}{|c|}{ Oxygen consumption } & \multirow{2}{*}{$\begin{array}{l}\text { B.M.R. } \\
-11 \\
-22\end{array}$} \\
\hline (L. S.) & $\begin{array}{l}\text { C. } \\
\mathrm{H} .\end{array}$ & & & & & & $\begin{array}{l}c c . / m i n . \\
230 \\
204\end{array}$ & $\begin{array}{c}\begin{array}{c}\text { per cent } \\
\text { change }\end{array} \\
-11\end{array}$ & \\
\hline (J. K.) & $\begin{array}{l}\text { C. } \\
\text { H. }\end{array}$ & 28 & $M$ & 177 & 73 & $\begin{array}{l}5.0 \\
7.3\end{array}$ & $\begin{array}{l}191 \\
225\end{array}$ & +18 & $\begin{array}{l}-26 \\
-14\end{array}$ \\
\hline (R. W.) & $\begin{array}{l}\text { C. } \\
\text { H. }\end{array}$ & 29 & $\mathrm{M}$ & 176 & 70 & $\begin{array}{r}5.2 \\
14.6\end{array}$ & $\begin{array}{l}243 \\
262\end{array}$ & +8 & $\begin{array}{l}-4 \\
+3\end{array}$ \\
\hline (A. V.) & $\begin{array}{l}\text { C. } \\
\text { H. }\end{array}$ & 28 & M & 189 & 73 & $\begin{array}{r}6.7 \\
14.2\end{array}$ & $\begin{array}{l}256 \\
233\end{array}$ & -9 & $\begin{array}{l}-5 \\
-14\end{array}$ \\
\hline (B. K.) & $\begin{array}{l}\text { C. } \\
\text { H. }\end{array}$ & 26 & M & 181 & 70 & $\begin{array}{r}5.8 \\
11.9\end{array}$ & $\begin{array}{l}272 \\
267\end{array}$ & -2 & $\begin{array}{l}+4 \\
+2\end{array}$ \\
\hline Means & $\begin{array}{l}\text { C. } \\
\text { H. }\end{array}$ & 28 & M & 179 & 73 & $\begin{array}{r}5.7 \\
12.5\end{array}$ & $\begin{array}{l}238.4 \\
238.2\end{array}$ & & $\begin{array}{l}-8.4 \\
-9.0\end{array}$ \\
\hline
\end{tabular}

Note: B.M.R. calculated on basis of 4.825 calories per liter of oxygen.

C. - Control.

H.-Hyperventilation.

tion was calculated from the difference between (a) the product of the expired gas volume and 20.93 per cent (this latter figure taken as the oxygen concentration in room air) and (b) the product of expired gas volume and the oxygen concentration of expired air as measured on the Pauling meter. No attempt was made to correct expired gas volume to inspired volume since in a series of preliminary experiments with expired gas volume analyzed by a Scholander gas analyzer, the correction amounted to only +1 per cent of expired volume. The maximal error in the estimation of oxygen consumption is \pm 10 per cent, and the average error is \pm 5 per cent.

Hyperventilation was entirely voluntary, and subjects attempted to regulate their respiratory rate in such a manner as to keep it 1.5 to 3 times the resting rate. Two subjects hyperventilated just to the point of vertigo. Hyperventilation lasted from six to 10 minutes.

The results as shown in Table II indicate that the mean respiratory volume was increased 2.2 times in hyperventilation over the mean resting volume; however, the mean oxygen consumptions are practically identical, being 238.4 and 238.2 cc., in rest and hyperventilation, respectively. The basal metabolic rate also fails to show any significant variation; the mean value in resting being
-8.4 per cent as compared to -9.0 per cent in hyperventilation.

It thus appears that moderate hyperventilation per se in a series of five determinations on apparently healthy young males has no significant effect on the oxygen consumption or basal metabolic rate.

\section{DISCUSSION}

Standards for determining the basal metabolic rate as a deviation from normal are now well accepted when the DuBois standards (1) are used whereby body surface area is considered. Failure to appreciate this relationship tends to invalidate experiments performed prior to 1916 . The method of indirect calorimetry using a closed circuit such as is commonly used for clinical determination of oxygen consumption was considered unreliable for our determinations because of the difficulty of interpreting a spirometer record when ventilation is excessive and because in that method a standard respiratory quotient is assumed.

There are many factors that affect the oxygen consumption and might lead to an error of interpretation of these results showing a markedly increased basal metabolic rate in diabetic acidosis. In the main, these are all of the well known factors that affect the basal metabolic rate. Fever will invariably increase the metabolic rate. There was 
no appreciable elevation of body temperature in the group studied. There is doubt that these patients were truly basal, though in many respects they might be considered more basal than the patients usually tested, for all were lethargic or hypoactive, all had been fasting for more than 12 hours and most had been in bed for more than 24 hours. The control group was not apparently in a more basal condition than was the experimental group. It is conceivable that, with the hyperventilation of these patients in acidosis, the actual muscular work involved in hyperventilation might contribute to the increased oxygen consumption. It has been demonstrated (12) that only 3.7 per cent of the oxygen consumed is used to satisfy the extra needs of hyperventilation alone up to a respiratory exchange of 22 liters per minute. Our findings in Table II fail to show any significant change in oxygen consumption as a result of moderate hyperventilation. Hyperventilation, therefore, does not apparently significantly affect the magnitude of the changes of the basal metabolic rate reported here. Only two patients had a respiratory pattern that could be considered Kussmaul in type.

Practically every patient was severely dehydrated and weighed less than he would under normal conditions. Therefore, using his assumed normal weight would be more reliable than the actual measured weight when dehydrated. It was found that a variation of 10 pounds of weight did not affect the calculated basal metabolic rate appreciably. The weight used in calculating the basal metabolic rate in these studies was the weight as measured after the first day of therapy when the previous dehydration had been corrected to a great extent. Had the admission weight been used, the calculated metabolic rate would have been even higher. It has been noted (13) that sleep itself tends to lower the basal metabolic rate 10 to 13 per cent. Since most patients in this group were lethargic and some of then sleeping, this factor would tend to make these results more valid in that the error would have been a result too low rather than too high. Mental effort has been shown to increase the basal metabolic rate only negligibly, while strong emotion caused an increase of only 5 to 10 per cent (13).

Fulton (14) has noted that hyperventilation in itself affects the carbon dioxide : oxygen ratio in such a manner that the determined respiratory quotient in patients who are hyperventilating may vary with this factor of hyperventilation irrespective of any true metabolic change. In addition to the calculations tabulated, the basal metabolic rate was also calculated for each patient using an assumed respiratory quotient of 0.82 . This served to raise the calculated basal metabolic rate in each case, so these figures were not used.

Thus every incidental factor which could reasonably have altered the metabolic rate in these patients appears incapable of explaining, in itself or in combination with others, the marked and statistically significant increase in oxygen consumption and metabolic rate which is found. The conclusion appears justified that diabetic acidosis is associated with a real increase in the oxygen consumption of the body as a whole. That this is not a uniform acceleration of metabolism involving all the tissues is indicated by previous work from this laboratory (15) which demonstrated a significant reduction in cerebral oxygen consumption in this condition. Diabetic acidosis is not the only state in which the oxygen consumption of the brain appears to behave independently of that of the body as a whole. Recently two groups working independently have found no cerebral counterpart to the increased total metabolism of hyperthyroidism $(16,17)$.

The significance of this increase in oxygen consumption in diabetic acidosis remains obscure. It may be of interest, however, to point out that this finding is compatible with the in vitro observations of Polis and associates (18) in this laboratory on a possible mechanism of insulin action. This group found insulin to be capable of increasing the efficiency of the synthesis of high energy phosphorous compounds with energy released by an oxidative process. If an important defect resulting from the relative insulin deficiency of diabetes were to reside in the conversion of oxidative energy to useful work through the energy-rich phosphate bond, then an acceleration of oxidative processes might be necessary to maintain normal cellular function in uncontrolled diabetes. This thesis is further supported by preliminary observations which have failed to demonstrate an increase in cellular uptake of $\mathrm{P}^{32}$ in the face of this increased rate of oxidation. 


\section{SUMMARY}

1. Total oxygen consumption and metabolic rate was studied in 11 patients in diabetic acidosis and in seven non-diabetic controls.

2. There is a marked and statistically highly significant increase in the metabolic rate of the group in diabetic acidosis compared with expected normal values and with values found in the non-diabetic controls.

3. Hyperventilation per se, in a series of five determinations on apparently healthy young males showed no significant effect on the oxygen consumption or basal metabolic rate.

4. The possible significance of these findings is discussed.

\section{ACKNOWLEDGMENT}

The authors wish to express their appreciation to Dr. Seymour Kety for his guidance in the preparation of this manuscript.

\section{REFERENCES}

1. DuBois, D., and DuBois, E. F., Clinical calorimetry. $\mathrm{X}$. A formula to estimate the approximate surface area if height and weight be known. Arch. Int. Med., 1916, 17, 863.

2. Allen, F. M., and DuBois, E. F., Clinical calorimetry. XVII. Metabolism and treatment in diabetes. Arch. Int. Med., 1916, 17, 1010.

3. Wilder, R. M., Boothby, W. M., and Beeler, C., Studies of the metabolism of diabetes. J. Biol. Chem., 1922, 51, 311.

4. Holten, C., The respiratory metabolism in diabetes and the influence of insulin upon it. J. Metabol. Researeh, 1924, 6, 1.

5. Hédon, L., Le quotient respiratoire et le métabolisme de base dans le diabète pancréatique expérimental. Arch. Internat. de Physiol., 1927, 29, 175.

6. Bernstein, S., and Falta, W., Über den einfluss der ernährungsweise auf den ruhenuchternumsatz bie normalen diabetischen individuen. Deutsches Arch. f. klin. Med., 1916, 121, 95.

7. Richardson, H. B., and Mason, E. H., Clinical calorimetry. XXXIII. The effect of fasting in diabetes as compared with a diet designed to replace the foodstuffs oxidized during a fast. J. Biol. Chem., 1923, 57, 587.

8. Duncan, G. G., in: Diseases of Metabolism, edited by Duncan, G. G. 'W. B. Saunders Co., Philadelphia, 1947, 2nd edition, p. 18.

9. Joslin, E. P., Root, H. F., White, P., Marble, A., and Bailey, C. C., The Treatment of Diabetes Mellitus. Lea \& Febiger, Philadelphia, 1946, p. 262.

10. DuBois, F. F., Basal Metabolism in Health and Disease. Lea \& Febiger, Philadelphia, 1936, p. 277.

11. Macleod, J. J. R., Physiology in Modern Medicine, edited by Bard, P. C. V. Mosby Co., St. Louis, 1938, 8th edition, p. 731 .

12. Müller, E. A., Michaelis, H. F., and Müller, A., Der energieaufwand für die atmung beim memschen. Arbeitsphysiol., 1942, 12, 192.

13. Best, C. H., and Taylor, N. B., Physiological Basis of Medical Practice. The Williams \& Wilkins Co., Baltimore, 1945, 4th edition, p. 522.

14. Howell, W. H., A Textbook of Physiology, edited by Fulton, J. F. W. B. Saunders Co., Philadelphia, 1949, 16th edition, p. 1004.

15. Kety, S. S., Polis, B. D., Nadler, C. S., and Schmidt, C. F., The blood flow and oxygen consumption of the human brain in diabetic acidosis and coma. J. Clin. Invest., 1948, 27, 500.

16. Sokoloff, L., Wechsler, R. L., Balls, K., and Kety, S. S., The relation of the cerebral $\mathrm{O}_{2}$ consumption to the total body metabolism in hyperthyroidism. J. Clin. Invest., 1950, 29, 847.

17. Scheinberg, P., Cerebral circulation and metabolism in hyperthyroidism. J. Clin. Invest., 1950, 29, 1010.

18. Polis, B. D., Polis, E., Kerrigan, M., and Jedeikin, L., Effect of insulin and adenosinetriphosphatase on a reaction coupling oxidation with phosphorylation. Arch. Biochem., 1949, 23, 505. 